\title{
Co and Co-Pt Nanoparticles Formed in Silica by lon Implantation
}

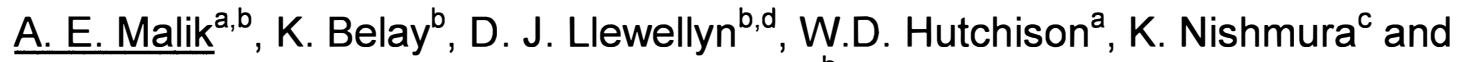 \\ R. Elliman ${ }^{b}$ \\ a School of Physical, Environmental and Mathematical Sciences, The University of New South Wales at \\ ADFA, Canberra ACT 2600. \\ ${ }^{\mathrm{b}}$ Electronic Materials Engineering Department, Research School of Physics and Engineering, Australian \\ National University, Canberra, ACT 0200, Australia. \\ ${ }^{\mathrm{C}}$ Graduate School of Science and Engineering, University of Toyama, Toyama, Japan. \\ b, d Centre for Advanced Microscopy, Australian National University, Canberra, ACT 0200, Australia.
} Corresponding author: Email aem109@anu.edu.au

\begin{abstract}
Nanoparticles of metallic cobalt and cobalt-platinum alloy have been synthesised via ion implantation and thermal annealing. The size and spatial distributions of the resulting nanoparticles were investigated as a function of annealing temperature, for temperatures up to $900^{\circ} \mathrm{C}$, and correlated with their magnetic properties.
\end{abstract}

1 Introduction: Co-Pt nanoparticles are of particular interest for ultra-highdensity magnetic recording media and have been produced by a range of thin film deposition techniques [4-5] (e.g. molecular beam epitaxy, electron beam evaporation, electron deposition etc) due to their magneto crystalline anisotropy, chemical stability and high Curie temperature [6]. Recent studies have investigated the synthesis of cobalt nanoparticles in silica by ion implantation [1-3] but few have investigated the magnetic properties of such particles or their alloys. In this study we report the synthesis of $\mathrm{Co}$ and Co-Pt alloy nanoparticles and the effect of alloying and processing on their magnetic properties.

2 Experimental: $\mathrm{Si}$ wafers with a $100 \mathrm{~nm}$ thick, thermally grown $\mathrm{SiO}_{2}$ surface layer were implanted with 50 $\mathrm{keV}$ Co ions or $100 \mathrm{keV} \mathrm{Pt}$ ions with fluences of $6 \times 10^{16}$ ions $/ \mathrm{cm}^{2}$, or for the Co-Pt alloy, sequentially implanted with $\mathrm{Co}$ and then $\mathrm{Pt}$ ions each with a fluence of $3 \times 10^{16}$ ions $/ \mathrm{cm}^{2}$. According to the Monte-Carlo ion-range simulation code SRIM 2007 [7], the average range of both $\mathrm{Co}$ and $\mathrm{Pt}$ ions in $\mathrm{SiO}_{2}$ is $\sim 43 \mathrm{~nm}$ for the above mentioned energies.

The implanted samples were annealed separately at $500^{\circ} \mathrm{C}, 700^{\circ} \mathrm{C}$, $900^{\circ} \mathrm{C}$ for 1 hour to study the effect of annealing temperature on the size and distribution of nanoparticles, which were determined from transmission electron microscopy of sample cross-sections.

3 Results and Discussion: Fig. 1 shows the TEM images of the Coimplanted sample as a function of annealing temperature. At low temperatures the nucleation and growth of nanoparticles is limited by the lack of diffusion and only small particles are observed, concentrated at the projected range of implanted cobalt distribution. As the annealing temperature increases, the size of the nanoparticles increases and some long-range transport of $\mathrm{Co}$ is observed. This is illustrated in Figs. 1b and $1 \mathrm{C}$ for samples annealed at $700^{\circ} \mathrm{C}$ and $900^{\circ} \mathrm{C}$, respectively. During 
annealing at $900^{\circ} \mathrm{C}$ cobalt atoms easily diffuse to the surface and $\mathrm{SiO}_{2} / \mathrm{Si}$ interface forming a bimodal or trimodal depth distribution as shown in fig. 1c.
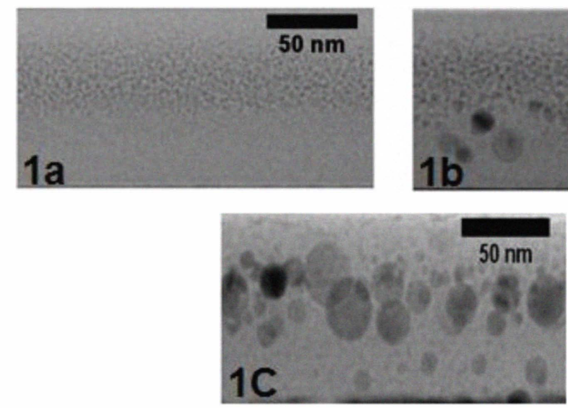

Fig. 1 Cross-sectional TEM images of Co implanted samples annealed at $500^{\circ} \mathrm{C}$ (1a), $700^{\circ} \mathrm{C}(1 \mathrm{~b})$ and $900^{\circ} \mathrm{C}(1 \mathrm{c})$ for one hour.
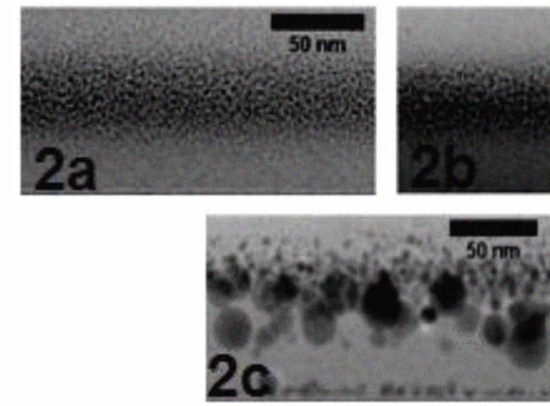

Fig. 2 Cross-sectional TEM images of Co-Pt implanted samples annealed at $500^{\circ} \mathrm{C}$ (1a), $700^{\circ} \mathrm{C}(1 \mathrm{~b})$ and $900^{\circ} \mathrm{C} \mathrm{(1c)}$ for one hour.

The evolution of nanoparticles in samples implanted with $\mathrm{Co}$ and $\mathrm{Pt}$ is shown in Fig. 2. Alloying of $\mathrm{Co}$ and $\mathrm{Pt}$ leads to smaller particles on average than for the equivalent total fluence of Co-only due to the low diffusivity of $\mathrm{Pt}$ in $\mathrm{SiO}_{2}$.

Magnetic characterisation of these samples was carried out with a maximum applied field of \pm 10000 Oe using a super conducting quantum interference device (SQUID) in hysteresis mode. The effect of size of nanoparticles and their type (i.e. metallic or alloy) on magnetization was observed. It was found that the CoPt alloy show an enhanced magnetic character in all the cases studied. Due to the addition of $\mathrm{Pt}$ to Co increased coercivity of the CoPt sample annealed at all the temperatures.

\section{References:}

[1] Gilliot M, En Naciri A, Johann L, Stoquert J P, Grob J J and Muller D 2007 J. Appl. Phys. 101014319.

[2] Orleans C D, Cerruti C, Estournes C, Grob C J J, Guille J L, Haas F, Muller D, Richard

Plouet M and Stoquert J P 2003 Nucl. Inst. Methods Phys. B 209 316.

[3] Mettei G, Maurizio C, de Julian C F, Mazzoldi P, Battaglin G, Canton P, Cattaruzza E, and Scian C 2006 Nucl. Inst. Methods Phys. B 250 206.

[4] Ferrate F, Liveri V. T, 2005 Coll. Surf. A 2597.

[5] Yuan F. T, Chang H. W, Liao W. M, Hsiao S. N, Chen S. K, Yao Y. D, 2007 Appl. Phys. 101 09K526.

[6] Vlasova N. I, Kandaurova G. S and Shchegoleva N. N, 2000 J. Magn. Magn. Mater. 222138.

[7] Ziegler F, Biersack J P, Littmark U 1985 The Stopping and Range of lons in Solids, (New-York: Pergamon) http://www.srim.org/. 